\title{
Sensory Cortical Population Dynamics Uniquely Track Behavior across Learning and Extinction
}

\author{
Anan Moran and Donald B. Katz \\ Psychology Department and Volen Center for Complex Systems, Brandeis University, Waltham, Massachusetts 02453
}

\begin{abstract}
Neural responses in many cortical regions encode information relevant to behavior: information that necessarily changes as that behavior changes with learning. Although such responses are reasonably theorized to be related to behavior causation, the true nature of that relationship cannot be clarified by simple learning studies, which show primarily that responses change with experience. Neural activity that truly tracks behavior (as opposed to simply changing with experience) will not only change with learning but also change back when that learning is extinguished. Here, we directly probed for this pattern, recording the activity of ensembles of gustatory cortical single neurons as rats that normally consumed sucrose avidly were trained first to reject it (i.e., conditioned taste aversion learning) and then to enjoy it again (i.e., extinction), all within $49 \mathrm{~h}$. Both learning and extinction altered cortical responses, consistent with the suggestion (based on indirect evidence) that extinction is a novel form of learning. But despite the fact that, as expected, postextinction single-neuron responses did not resemble "naive responses," ensemble response dynamics changed with learning and reverted with extinction: both the speed of stimulus processing and the relationships among ensemble responses to the different stimuli tracked behavioral relevance. These data suggest that population coding is linked to behavior with a fidelity that single-neuron coding is not.
\end{abstract}

Key words: condition taste aversion; dynamics; hidden Markov models; learning; neural network

\section{Introduction}

Experience continuously shapes the perception and behavior of all animals, including humans. Songs that evoke positive emotions and actions after a couple's wedding evoke something different after a brutal divorce. You avoid your mother's oh-sodelicious cake after it causes you food poisoning.

Even innocuous exposure to a stimulus, to the fact that it appears reliably in a particular context, for instance (Orban et al., 2008), changes that stimulus' impact on behavior. Particularly well-studied in this realm is the fact that merely experiencing a stimulus as "safe" will cause an animal to lose aversions to that stimulus (Rescorla, 1997; Bouton, 2004); a few experiences that end without vomiting will restore your faith in mother's cake. This phenomenon, called extinction, is underlain by plasticity processes similar to those governing other learning contexts; it is thought to be not "forgetting" but a novel form of learning that overlays the original learning (McCaughey et al., 1997; Quirk, 2002; Rescorla, 2002; Bahar et al., 2003; Santini et al., 2004; Jirenhed et al., 2007). This evidence suggests (but does not prove) that single-neuron responses to learning-related stimuli should

Received Aug. 4, 2013; revised Dec. 1, 2013; accepted Dec. 5, 2013.

Author contributions: A.M. and D.B.K. designed research;A.M. performed research;A.M. analyzed data; A.M. and D.B.K. wrote the paper.

This work was supported by National Institutes of Health Grant DC006666 to D.B.K. and the Swartz Foundation (A.M.). We thank Gina Turrigiano and Leslie Griffith for their valuable comments and discussions. We thank Veronica Flores for help with figure artwork.

The authors declare no competing financial interests.

Correspondence should be addressed to Dr. Anan Moran, Psychology Department, Brandeis University, 415 South Street, Waltham, MA 02453. E-mail: amoran@brandeis.edu.

DOI:10.1523/JNEUROSCI.3331-13.2014

Copyright $\odot 2014$ the authors $\quad 0270-6474 / 14 / 341248-10 \$ 15.00 / 0$ differ in the naive and postextinction animal, only indirectly tracking stimulus relevance, and leaving integrative and motor regions to use two different patterns of activity to drive similar behaviors.

Of course, this is not the only possibility. Brain function has frequently been suggested to be better understood in terms of the dynamics of population/network coding: of activities of neurons related directly to one another (e.g., Deadwyler and Hampson, 1997; Christensen et al., 2000; Mazor and Laurent, 2005; Barnes et al., 2008); thus, it is possible that ensemble analyses might reveal similarities between naive and postextinction sensory responses that are invisible in single-neuron activity. As of now, however, the few examples of such phenomena (e.g., Churchland et al., 2010, 2012) have largely come from regions far from sensory processing and relatively unaffected by perceptual learning.

Here, we analyzed sensory-cortical responses produced as rats progressed through a novel, multistimulus version of a taste learning task in which learning and extinction were achieved in as little as $49 \mathrm{~h}$. A subset of the neural sample was isolated for the entire $2 \mathrm{~d}$ progression of sessions, such that we could directly confirm that single-neuron stimulus responses indeed did not return to their "naive" state with extinction: that extinction did not equal "unlearning." Nonetheless, ensemble analyses revealed that coherent firing rate dynamics in simultaneously recorded neural ensembles (Abeles et al., 1995; Freeman, 2000; Jones et al., 2007; Kemere et al., 2008; Ponce-Alvarez et al., 2012) track behavior, speeding up with conditioning and slowing down with extinction. Furthermore, session-specific ensemble codes keyed to these dynamics correctly predicted behavioral relevance of each stimulus at each phase of training. We conclude that, despite the fact that single-neuron responses change with each new ex- 


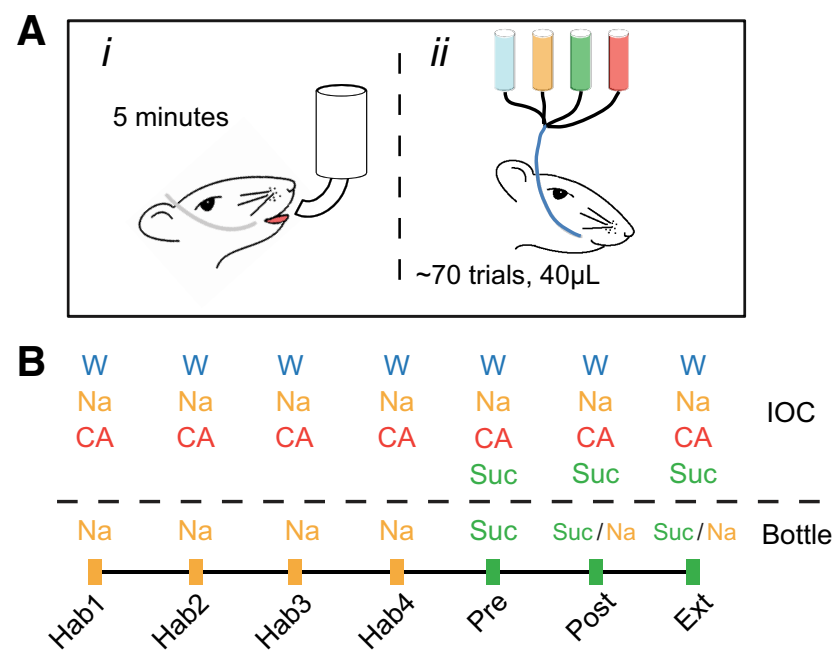

Figure 1. Learning/extinction protocol. $\boldsymbol{A}$, The two phases in each daily session used in behavioral training. In the first phase rats drank from a lick-spout for $5 \mathrm{~min}$ (left); and in the second phase, a battery of tastes were delivered through an IOC (right) directly onto the rats' tongue. $\boldsymbol{B}$, The tastes that were offered in the bottle and delivered through the IOC in each trial: 4 habituation sessions (Hab1-4). In the following session, rats were given a (TA (Pre), after which the learned aversion was evaluated (Post), and 1-2 further sessions tested the fading of that aversion (Ext). Suc, Sucrose; $\mathrm{Na}, \mathrm{NaCl}$; $\mathrm{CA}$, citric acid; W, water.

perience, ensemble response dynamics continue to accurately and stably reflect a sensory stimulus' relationship to behavior.

\section{Materials and Methods}

Surgery

Female rats were anesthetized using an intraperitoneal injection of a ketamine/xylazine mixture (100 and $10 \mathrm{mg} / \mathrm{kg}$, respectively; maintenance: one-third induction dose every $1.25 \mathrm{~h}$ ). The anesthetized rat was placed in a stereotaxic frame, its scalp excised, and holes bored in its skull for the insertion of self-tapping ground screws and a pair of 16 formvarcoated, $25 \mu \mathrm{m}$ nichrome wire bundles attached to a mini-microdrive (Katz et al., 2001) $0.5 \mathrm{~mm}$ above taste cortex (anteroposterior $1.4 \mathrm{~mm}$ and mediolateral $-5 \mathrm{~mm}$ from bregma; dorsoventral $-4.5 \mathrm{~mm}$ from dura). Assemblies, including two intraoral cannulae (IOCs; flexible plastic tubing inserted close to the tongue in the cheek) were cemented to the skull using dental acrylic.

\section{Behavioral procedure}

After $7 \mathrm{~d}$ of recovery from surgery, rats were adapted to $30 \mathrm{~min}$ of fluid access in the morning recording sessions and $2 \mathrm{~h}$ of access several hours later (to ensure proper hydration). Recording sessions were divided into two parts: an initial behavior assessment followed by a neuronal response session (Fig. 1). In the behavior part (Fig. 1Ai), rats were allowed to drink from a single bottle in the recording chamber where both consumption and lick count were recorded. After a 5 min break, $\sim 70$ pseudorandomly selected deliveries (with equal probability) of a battery of tastes (40 $\mu$ l per delivery, one stimulus/15 s) were made through the IOC directly onto the tongues of the rats to assess corresponding neuronal responses (Fig. 1Aii). The specific sequence of daily sessions was as follows (Fig. 1B):

Habituation ( $\mathrm{Hab})$. In the first 4 sessions, rats were offered $\mathrm{NaCl}(\mathrm{Na}$, $0.1 \mathrm{~m})$ through the bottle, and water, $\mathrm{Na}$, and citric acid (CA, $0.2 \mathrm{M})$ through the IOC.

Preconditioning (Pre). In the morning of the fifth day, $\mathrm{Na}$ at the lick spout was replaced with sucrose (Suc, $0.2 \mathrm{M}$ ), which was also added to the battery of tastes delivered through the IOC. Immediately afterward, rats were injected intraperitoneally with $\mathrm{LiCl}(0.15 \mathrm{M}, 2 \%$ body weight $)$ to induce malaise. This procedure caused rats to develop a selective association (conditioned taste aversion [CTA]) between malaise and novel Suc (De la Casa and Lubow, 1995; Berman and Dudai, 2001). Control rats follow the same procedure excluding the $\mathrm{LiCl}$ injection and, thus, did not develop Suc aversion.

Postconditioning (Post). The day after Pre, we offered the rats first Suc and then $\mathrm{Na}$ from the bottle ( $5 \mathrm{~min}$ each). Only rats that showed specific conditioning to Suc (consumption $\leq 25 \%$ of Pre, no change in Na consumption) were further analyzed (few rats failed to meet this criterion); to maximize comparability of Pre and Post neural responses, Na was withdrawn once the sum of $\mathrm{Na}$ and Suc licks in Post was equal to the licks in Pre. Suc, Na, CA, and water were then offered through the IOC. The Suc delivered through the IOC, and the intermingling of Suc with other (safe) tastes ensured quick extinction of the Suc aversion.

Extinction (Ext). After Post, the same procedure was repeated until Suc was consumed in at least $90 \%$ of pre-CTA volume (Berman and Dudai, 2001). Reaching this level took one or two sessions.

Behavioral and electrophysiological data, although collected in the same session, were not collected at the same time. This means that we cannot with $100 \%$ certainty claim that the preference/palatability structure ascertained in one test holds for the other. This uncertainty, however, only serves to make our analysis more conservative (the change in task should, if anything, reduce our ability to discern brain-behavior correlations), and thus makes the strong brain-behavior correlations that we do observe (Sadacca et al., 2012) much more interpretable. The fact that preference emerges with similar time courses in licking tasks and electrophysiology (Maier and Katz, 2013) further adds to our confidence that the two are driven by the same underlying process.

\section{Electrophysiology}

Differential recordings made during IOC taste deliveries were fed into a parallel processor capable of digitizing up to 32 signals at $40 \mathrm{kHz}$ simultaneously (Plexon). Discriminable action potentials of no less than 3:1 signal-to-noise ratio were isolated online from each signal using an amplitude criterion in cooperation with a template algorithm (Nicolelis et al., 2003). Discriminations were checked continuously throughout each session. Time-stamped records of stimulus onset and neuronal spikes were saved digitally, as were all sampled spike waveforms and the discrimination file. Off-line reanalysis incorporating 3D cluster-cutting techniques confirmed and corrected online discriminations. Using these techniques, we have previously described neural activity that, when analyzed using classic techniques, accords well with what has previously been known of cortical single neurons (Katz et al., 2001; Fontanini and Katz, 2006).

\section{Evaluation of single-neuron stability across days}

To determine whether a waveform recorded from a single electrode for multiple sessions represented the same single neuron, we used a spike shape analysis brought to bear successfully in several previous studies (Nicolelis et al., 2003; Grossman et al., 2008; Herry et al., 2008). The multidimensional sampled shape of each spike was projected into 2 dimensions with principal component analysis. Projections of all spikes from two sessions onto the same 2D plane formed either two partly/ wholly separate clusters (indicating that they were different neurons) or completely overlain clusters suggestive of the records from a single neuron recorded on consecutive days. A nonparametric clustering statistic (" $J_{3}$ ") was used to statistically quantify the separation of clusters. It is calculated as follows: Let $S_{k_{i}}$ be the 2D projection of spike $i$ in session $k$, let $\mathrm{m}_{k}$ be the mean $2 \mathrm{D}$ vector of the $k$ th session with $N_{k}$ spikes, let $m$ be the overall projection point mean, and let $\|\cdot\|$ be the Euclidian distance, then:

$$
\begin{gathered}
J_{1}=\sum_{k} \sum_{k_{i}}\left\|s_{k_{i}}-m_{k}\right\|^{2}, \\
J_{2}=\sum_{k} N_{k}\left\|m_{k}-m\right\|^{2}, \\
J_{3}=J_{2} / J_{1},
\end{gathered}
$$

$J_{3}$ is maximal when cluster separation is high and each cluster is tightly packed, and it is trivial to test the significance of this separation (i.e., of the hypothesis that the two waveforms are not identical).

In our situation, we sought to test precisely the opposite hypothesis: that we had achieved isolation of the same unit across days. It is of course impossible to prove to $100 \%$ certainty that two values are identical, but 


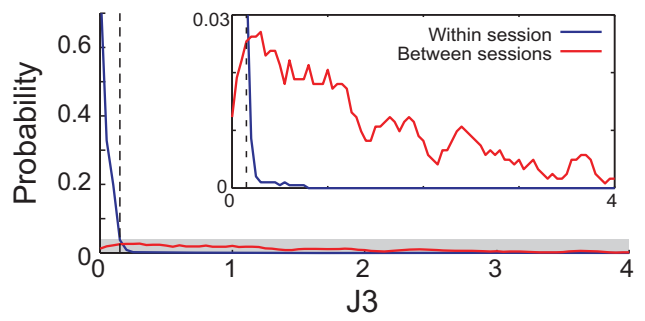

Figure 2. Within- and between-session $J_{3}$ statistic distributions. The within-session distribution (blue) displays a rapid decline from a maximum near zero, consistent with the isolation of a single waveform. The dashed vertical line indicates the 95th percentile of this distribution. The between-session $J_{3}$ statistic distribution (red) was much broader, indicating that only a small fraction of these isolations were as stable between sessions as $95 \%$ of the within-session isolations. This small fraction of isolations were deemed "held neurons." Inset, Grayed area $\left(N_{\text {within }}=383, N_{\text {Between }}=244\right)$.

use of a highly conservative criterion ensured that only highly similar spike shapes were deemed to indicate the survival of a neuron. We generated this criterion empirically by calculating $J_{3}$ between clusters created by taking waveforms from the first and last thirds of every single neuron's activity recorded within a single session (i.e., two clusters created from one neuron's firing within a single hour). Only neurons for which the between-session $J_{3}$ value was less than the 95th percentile value of $J_{3}$ calculated for that criterion analysis were categorized as held across those sessions. Figure 2 displays these data; the within-session distributions for Pre, Post, and Ext sessions were essentially identical to one another. The distributions shown are identical for different sessions and different between-session comparisons.

\section{Single-neuron responsiveness to sucrose}

To evaluate Suc response changes across sessions, we first divided both session's responses into ten $250 \mathrm{~ms}$ bins and applied two-way ANOVAs with session and time as factors (Piette et al., 2012; Sadacca et al., 2012): significant $(p<0.01)$ main effects for session defined a "response change;" significant session $\times$ time interactions defined a "temporal code change." In the case of neurons held across all 3 sessions, post hoc $t$ tests assessed whether changes were restricted to a particular pairs of the sessions.

An analogous analysis, brought to bear on multiple taste responses from single sessions (Pre, Post, or Ext), allowed us to determine whether a neuron produced sucrose-specific responses (and, if so, whether the specificity was in overall firing rates or temporally specific).

\section{Poisson hidden Markov models (HMMs)}

We assessed the timing of underlying states using a Poissonian HMM (Rabiner, 1989; Jones et al., 2007; Kemere et al., 2008), containing 5 fully interconnected baseline states (Kemere et al., 2008) that were each connected in a feedforward manner to 4 pairs of states (early and late), one pair for each taste stimulus. We chose to include 5 baseline states so that we could account for any fluctuations in the spontaneous firing rates of the neurons, and to maximize comparability to previous experiments (specifically, Kemere et al., 2008). We found, however, that our spontaneous firing rates were much less variable than those described previously, perhaps because of species differences; the results described below were unchanged if the number of baseline states was reduced.

Extensive research from our laboratory (e.g., Katz et al., 2001; Fontanini and Katz, 2006; Piette et al., 2012; Sadacca et al., 2012; Maier and Katz, 2013) suggests that cortical taste processing consists of two distinct chemosensory coding "epochs." This fact, and the limited number of fluid stimuli that can be delivered to awake rats (which in turn limits the ability of the HMM to converge), led us to restrict our search for the optimal parameters (state transition probability and firing rate matrices) capable of describing the data to this specific model design, rather than searching the entire model space. Training was performed separately for each session using the entire dataset of simultaneously recorded singletrial ensemble spike trains ( -200 to $2500 \mathrm{~ms}$ after stimulus delivery) across all stimuli.
Spike trains were first compiled into $10 \mathrm{~ms}$ bins to produce spike count sequences. Probability of transitions from each baseline state to each other baseline state and to each taste's early state was initialized to be equal. The initial probability of staying in the early state was randomly drawn from between 0.94 and 0.999 (the complementary probability represented the likelihood of transition to the same taste's late state, which served as a sink state). Firing rates for all five baseline states were initialized to the mean spontaneous rates. Early state firing rates were initialized to that neuron's mean firing rate of that taste's trials for the first $1000 \mathrm{~ms}$ of poststimulus time, and late state firing rates were similarly initialized using the 1000-2500 ms time range.

Training of the HMM began with conversion of the neuronal spike counts into probabilities using the Poisson distribution and the estimated neuronal firing rate (plus/minus random noise); this was the only step in which the poissonian assumption was used. This initial step was followed by application of the regular forward-backward algorithm; the EM procedure incrementally refined the firing rate and the state transition matrix parameters. We repeated this HMM training procedure 25 times, and the final state transitions and firing rate matrices with the highest likelihood were retained. We then calculated the posterior probability that the ensemble was in each of the states at each point in time for each trial. The ensemble of neurons was considered to be in state $S_{i}$ if the probability of $S_{i}$ was $>80 \%$ (a criterion that can lead to trials with 2,1 , or 0 valid states).

To determine whether sucrose responses more closely resembled $\mathrm{Na}$ or CA responses, we reanalyzed the data using a reduced HMM (see Fig. $8 A$ ) with transition probabilities to the early states of sucrose and water set to zero.

\section{Multidimensional scaling}

Multidimensional scaling (MDS), a common data reduction technique, allowed us to visualize the differences between state-specific ensemble responses in two (or higher, see below) dimensions; a shorter distance between two points in the MDS solution indicates higher similarity between population responses. Each row in the initial matrix contained the firing rates of each of the neurons to a one of the tastes in a specific session. The raw matrix, which contained 12 rows ( 4 tastes $\times 3$ sessions), was transformed into a $12 \times 12$ symmetric matrix by calculating the correlation between these rows. This (all-positive) correlation matrix was then converted to a dissimilarity matrix by subtracting it from the $12 \times 12$ matrix of ones.

Despite the fact that we used MDS to visualize the between-taste neuronal response correlations, there was no significant loss of information between the raw data and the MDS used to calculate the distances. To analyze the relation between taste position and composition across sessions, we calculated the relative distance of sucrose to $\mathrm{CA}$ and $\mathrm{Na}$ for each session, using the full-dimensional solution (i.e., 2D projections were used for display purposes only).

$$
D_{k}=\frac{d(S u c, C A)}{d(S u c, N a C l)}, k \in\{\text { pre, post }, \text { ext }\}
$$

where $d()$ is the Euclidean distance in the full dimensional solution, calculated separately for each session. Euclidean distances were used here to deemphasize the weight of non-taste-discriminating and low response-rate neurons in the distance measure. Lower values for D indicate that response patterns of sucrose are more correlated with $\mathrm{Na}$ than with CA, and higher values indicate the opposite. Further analysis tested whether the multiple relationships between the tastes was most similar between Pre and Ext, regardless of orientation or scale in the full response space, by calculating the 6 Euclidian distances among the 4 tastes for each of the sessions:

$$
d_{k}\left(T_{i}, T_{j}\right), 1 \leq k \leq 3,1 \leq i \leq 3,2 \leq j \leq 4, i<j
$$

where $k$ is a session index, and $i$ and $j$ are taste indices. Let

$$
m x d_{k}=\max \left(d_{k}\left(T_{i}, T_{j}\right)\right) \text { for each } \mathrm{k},
$$

Then for each distance its normalized form would be, 


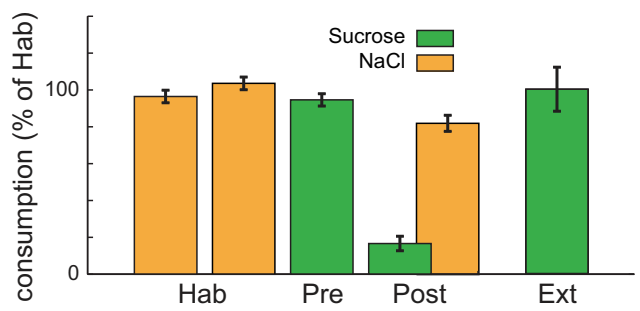

Figure 3. Behavior. Normalized consumption of sucrose and $\mathrm{NaCl}$ across sessions in which rats developed CTAs to Suc and had that conditioning extinguished. $N=6$. Error bars indicate SEM. Each rat's consumption was normalized to mean consumption during the last two habituation days.

$$
N d_{k_{i, j}}=\frac{d_{k}\left(T_{i}, T_{j}\right)}{m x d_{k}}
$$

Then we could compare the overall similarity between tastes composition of two sessions $k$ and $k^{\prime}$ by calculating the mean of the absolute difference between the normalized distances of all tastes.

$D_{k, k^{\prime}}=\left\langle\left|N d_{k_{i, j}}-N d_{k^{\prime}, j}\right|\right\rangle$ for all the 6 valid

$$
\text { combination of } i \text { and } j \text { as in Eq. } 5 .
$$

While statistics were performed on the full-dimensionality solution, evidence suggests that reduction to 2D (see Fig. 9) does not appreciably distort the solution. Not only has our previous use of similar multivariate data revealed a strong correlation between neural responses and behavior (Sadacca et al., 2012), suggesting reliability of the approach; in addition, MDS performed on this matrix had a stress value of 0.02 , indicating a high information similarity between the data presented on the $2 \mathrm{D}$ plane and the full correlation matrix, despite the dimensionality reduction.

\section{Results}

Rats quickly learn and extinguish a CTA to sucrose

We developed a multistimulus version of a combined CTA/extinction protocol; rats $(N=6)$ that initially liked sucrose (Suc) were taught to dislike it via pairing with injections of the emetic $\mathrm{LiCl}$, and then to like it again via pairings with "no emesis," in as little as $49 \mathrm{~h}$. A squad of control rats $(N=5)$ received similar treatment, but without the $\mathrm{LiCl}$ injection, such that no learning occurred.

The behavioral results for the experimental group are shown in Figure 3. By the third and fourth habituation sessions (Hab), stable drinking of palatable $\mathrm{NaCl}(\mathrm{Na})$ from the bottle had been achieved. On the fifth, preconditioning (Pre), session, Suc replaced $\mathrm{Na}$ in the bottle (and was included in the battery of IOCdelivered tastes that already included $\mathrm{Na}, \mathrm{CA}$, and water) and consumed avidly. The malaise subsequently induced via an injection of LiCl, however, greatly reduced Suc consumption in the postconditioning (Post) session without affecting Na consumption: rats learned a sucrose-specific CTA (prior familiarization to $\mathrm{CA}$ and $\mathrm{Na}$ assured that CTAs were specific to Suc, and thus that we could directly compare neuronal responses to all IOCdelivered stimuli without impairing conditioning). As expected, no decrement in sucrose consumption was noted in control rats.

The same procedure was repeated until a rat consumed at least 90\% of their Pre session Suc consumption (usually in a single day, and in two at most); this session was defined as the extinction (Ext) session. This ensured that all Ext responses analyzed below were collected from rats for which Suc was once again "safe."
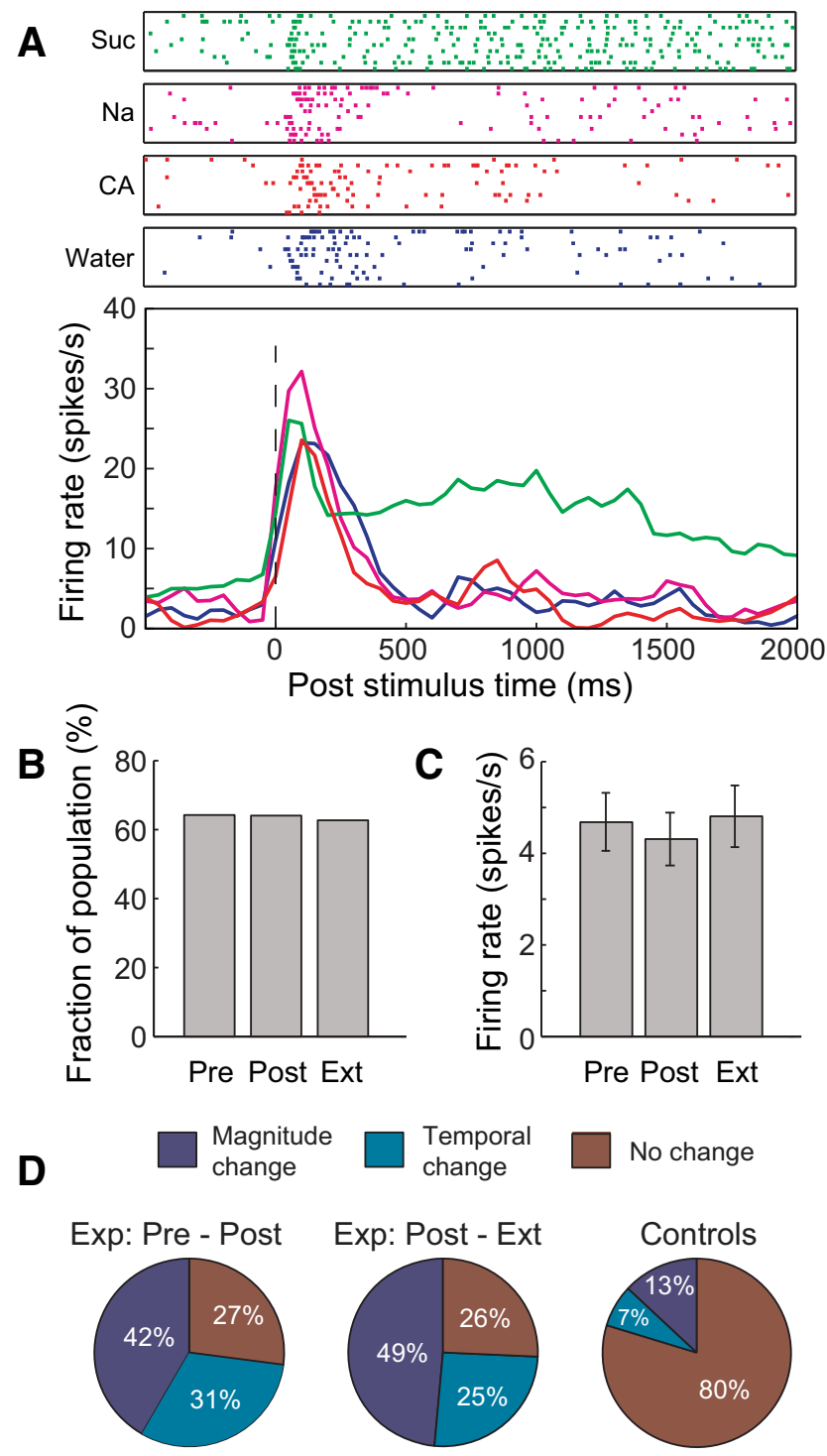

Figure 4. Single-neuron responses to sucrose change across sessions. $A$, Spike-time rasters (top) and PSTHs (bottom) for an example cortical neuron's responses to water, Na, Suc, and CA in Pre. $B$, Similar fractions of the single-neuron sample are taste responsive in each session $\left(\chi^{2}(2, N=383)<1\right) . C$, Average sucrose-induced firing rates are similar for all sessions $(F(2$, $N=383$ ) $<1$ ). $\boldsymbol{D}$, Percentages of Suc responses that changed (in overall average rate or temporal code) between pairs of sessions in neurons held for $\geq 24 \mathrm{~h}$. Controls differ from both pairs of sessions of conditioned rats ( $\chi^{2}$ test, $p<10^{-13}, N_{\text {Pre-Post }}=48, N_{\text {Post-Ext }}=35$, $N_{\text {controls }}=69$ ).

\section{Cortical single-neuron responses change with CTA, and change further with extinction}

We recorded taste responses from ensembles of single neurons $\left(21.16 \pm 7.76\right.$ neurons/session, $N_{\text {single neurons }}=383, N_{\text {ensembles }}=$ 18, experimental group) in primary taste (granular/dysgranular/ agranular insular) cortex, responses that are known to code taste information, including the palatability/aversiveness of tastes (Katz et al., 2001; Fontanini and Katz, 2006; Piette et al., 2012; Sadacca et al., 2012), and to change that coding with learning (Yasoshima and Yamamoto, 1998; Grossman et al., 2008) from bilaterally implanted bundles of microwires. Consistent with previous reports (Yamamoto et al., 1985; Katz et al., 2001), many of these neurons produced Suc-specific responses (for a representative set of peristimulus time histograms [PSTH], see Fig. 4A). 

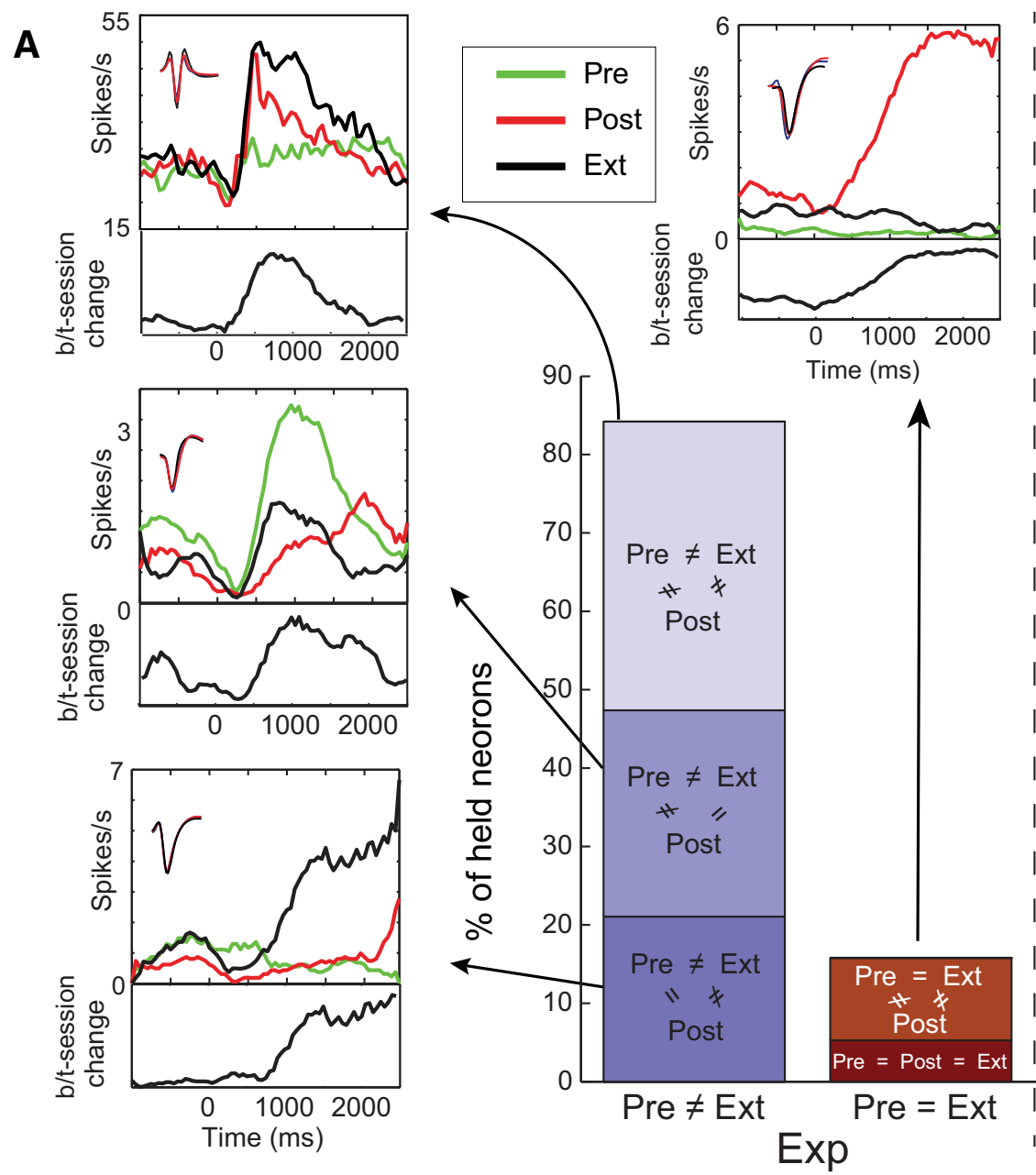

B

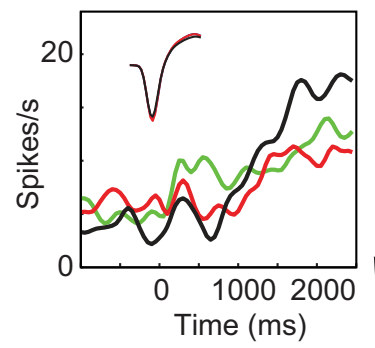

I Pre
Pre $=$ Ext

Post

Pre $=$ Ext

$*$
Post

Figure 5. Single neurons firing does not track behavioral responses to sucrose in conditioned rats. $\boldsymbol{A}$, Ext and Pre responses were similar for only a small minority of neurons held for $49 \mathrm{~h}$ in the conditioned rats group (bar chart). Suc PSTHs surrounding the bar plot depict examples of each observed pattern (e.g., Pre = Post, but neither = Ext). Insets, Neuron spike shape across days. Panels below PSTHs, Average differences (in sucrose-induced spike rate) between sessions. $\boldsymbol{B}$, In the control group $(N=5)$, the vast majority of held neurons $(N=18)$ retain their responses to sucrose across three consecutive days, in contrast to the conditioned group $\left(\chi^{2}(1, N=37)=58.5, p<10^{-13}\right)$.

Although neither the number of nor the average magnitude of these responses changed from session to session for either conditioned (Fig. $4 B, C ; \chi^{2}(2, N=383)<1, F(2, N=383)<1$, respectively) or control rats $\left(\chi^{2}(2, N=175)<1, F(2, N=\right.$ $175)<1$, respectively; data not shown), inspection of neurons that remained isolated across a $24 \mathrm{~h}$ period revealed, consistent with previous reports (Yasoshima and Yamamoto, 1998; Grossman et al., 2008), that learning changed overall response magnitudes and time courses of many (73\% of 48 neurons held from Pre to Post) Suc responses (Fig. $4 D$, left); many ( $74 \%$ of the 35 neurons held from Post to Ext) responses also changed with extinction (Fig. $4 D$, middle). No within-session (e.g., first half vs second half of session) changes were noted, and between-session firing-rate increases and decreases were similar in magnitude, such that no effects were observed in across-neuron averages (Fig. $4 B, C$ ).

The same analysis revealed much greater response stability for neurons recorded from control rats (in which no learning was induced): only a small minority of Suc responses (20\% of 69 neurons) changed across $24 \mathrm{~h}$ (Fig. $4 D$, right), significantly lower percentage than observed in trained animals $\left(\chi^{2}\right.$ test, $\left.p<10^{-13}\right)$. This result makes it clear that the single-neuron response plasticity observed in trained rats was learning-related, and validates our contention that we were able to hold neurons across sessions.
To directly test the prediction that extinction is a novel learning experience rather than "unlearning," we proceeded to an analysis of neurons $(N=19)$ held for $49 \mathrm{~h}$. This examination confirmed that responses recorded in Pre do not resemble those recorded in Ext more than those recorded in Post (Fig. 5A): only $15.8 \%$ of Suc responses were the same in Pre and Ext, and only $10.5 \%$ of the responses that changed between Pre and Post changed back between Post and Ext (bar graph); this percentage is low enough to reflect chance processes, and in light of our control data provides relatively little support for the hypothesis that single-neuron responses follow behavior. The sets of PSTHs surrounding the bar graph provide examples of each observed pattern: Suc responses that changed significantly (according to two-way ANOVAs for session and poststimulus time) between at least one pair of sessions. The vast majority $(84.2 \%)$ produced distinct Suc responses in Pre and Ext.

Plots below each set of PSTHs in Figure $5 \mathrm{~A}$ present the average magnitudes of between-session changes for each neuron. These changes were reliably late, appearing $0.5 \mathrm{~s}$ or more after stimulus delivery, the period previously shown (Katz et al., 2001; Fontanini and Katz, 2006; Piette et al., 2012; Sadacca et al., 2012; Maier and Katz, 2013) to reflect current palatability (see also Fig. 9). This concordance with earlier work represents further support for our basic assertion that the observed response changes reflect 

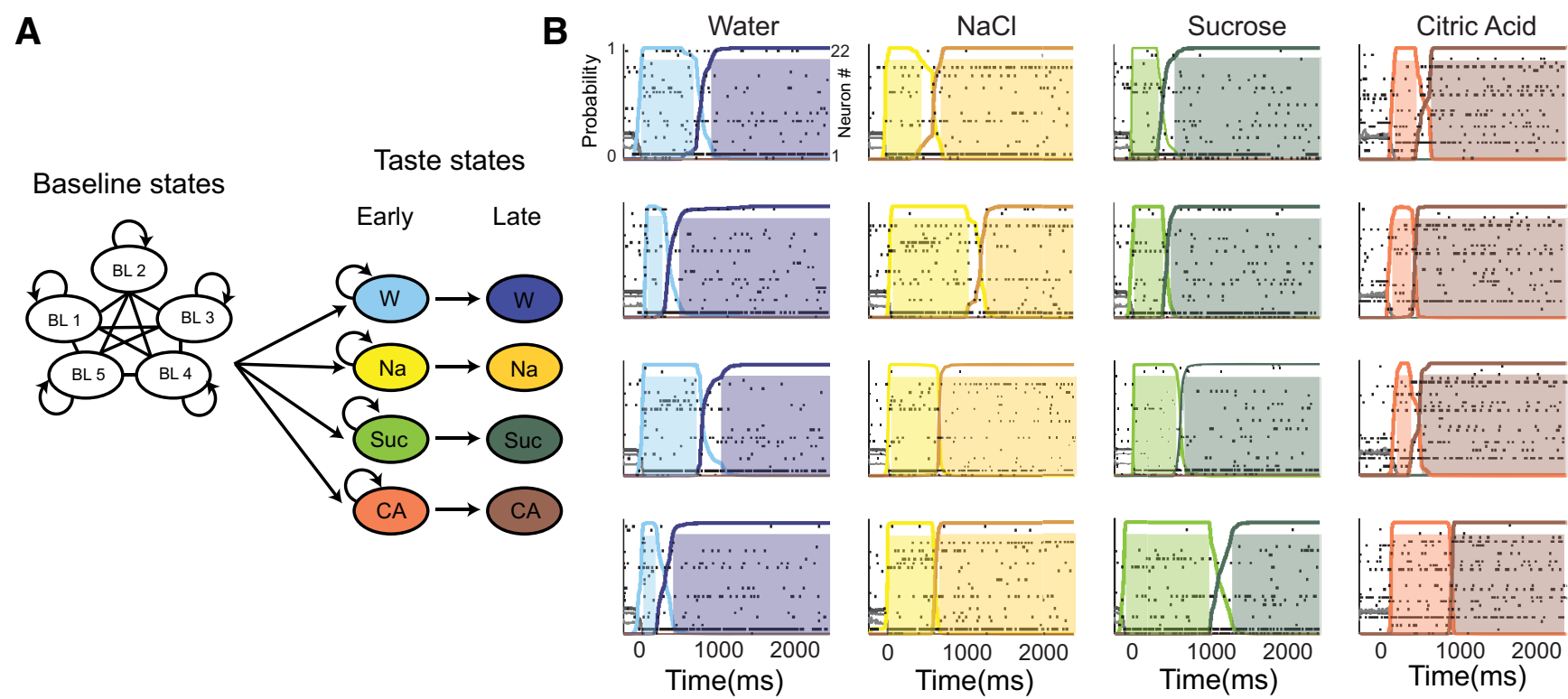

Figure 6. HMM. $\boldsymbol{A}$, The HMM used to analyze ensemble responses to each stimulus, including 5 baseline states and 4 pairs (one/taste) of driven states. $\boldsymbol{B}$, Example ensemble responses characterized using this HMM: the colored lines overlain on the ensemble of spike trains (each row is a neuron, $y$-axis) indicate the calculated probability that the ensemble is in that particular state (color coding as in $\boldsymbol{A}$ ); shaded regions represent time periods during which the dominant state has $p>0.8$. The same state sequence was observed for each trial of a stimulus, but interstate transition timing varied from trial to trial.

genuine single-neuron response plasticity: changes arising from poor isolation would have occurred with equal likelihood in earlier portions of the responses, rather than being restricted to the epoch in which responses are reliably related to palatability (the property that is changed by CTA).

We performed two separate control analyses to further test the assertion that learning and extinction changed responses independently. First, an examination of Pre-Ext changes in CA responses recorded from the same neurons and in the same sessions showed these responses to be far more stable than Suc responses. Although it is simplistic to expect $100 \%$ of any responses to remain unchanged across 49 h (below we present empirical rationale for expecting Suc conditioning and extinction to change some CA responses) (Ziv et al., 2013), over 4 times as many CA responses $(63 \%)$ as Suc responses were stable across learning, consistent with our interpretation of those Suc response changes as being learning-related.

Second, data from the control rats that were exposed to the same procedure but not trained to dislike sucrose revealed (Fig. $5 B$ ), as expected, far fewer differences between Pre and Ext compared with conditioned rats: fully $79 \%$ of the control Suc responses were similar in Pre and Ext, and 67\% did not change at all across the 3 consecutive days $\left(\chi^{2}(1, N=37)=58.5, p<10^{-13}\right.$, one representative example is shown). Thus, and as predicted by indirect evidence, whereas behavioral reactions to Suc were relatively similar in Pre and Ext, single-neuron responses to Suc were not.

\section{The speed of cortical ensemble sucrose processing tracks behavioral relevance}

If single-neuron Suc responses in Ext do not resemble singleneuron Suc responses in Pre, is there some level at which the sensory cortical networks can be seen to produce postextinction output resembling naive output, even if this pattern is not apparent in single-neuron firing?

Indeed, further analysis focused on cooperative processing among simultaneously recorded neurons uncovered just such hidden links to behavior. These analyses made use of HMM, which in several recent studies have revealed ensembles of neurons working together to process sensory and motor information in ways that cannot be detected in analyses of single neurons (Abeles et al., 1995; Jones et al., 2007; Kemere et al., 2008; PonceAlvarez et al., 2012). Specifically, HMM analysis has been used to reveal ensemble responses to be reliable sequences of stable firing rate states separated by sudden coherent state transitions, the timing of which varies from trial to trial such that they are specifically obscured in single-neuron analyses that average across trials (Jones et al., 2007; Miller and Katz, 2010, 2013). We hypothesized that, regardless of whether the responses of individual neurons faithfully track behavior across learning and extinction, these dynamic ensemble responses would do so.

We applied a specific Poissonian HMM (Jones et al., 2007; Kemere et al., 2008) to whole ensemble responses recorded in each session, in which baseline states (Kemere et al., 2008) were connected in a feedforward manner to each of 4 pairs (1/stimulus) of early and late taste-driven states (Fig. 6A), in line with previous work revealing two distinct taste-coding "epochs" within cortical responses (Katz et al., 2001; Fontanini and Katz, 2006; Piette et al., 2012; Sadacca et al., 2012; Maier and Katz, 2013). Analyzed thus, ensemble taste responses in Pre could be observed (consistent with previous report; see Jones et al., 2007) to evolve through a reliable, taste-specific pair of states, transitions between which consisted of abrupt firing rate changes in large percentages of simultaneously recorded neurons. Neural ensembles progressed through both states in the vast majority of trials, but the latency of the between-state transition was subject to substantial trial-to-trial variability (Fig. 6B).

Basic aspects of these dynamics were changed by CTA. State sequences evoked by Suc were somewhat less reliable in Post than in Pre (Fig. $7 A$ ): trials with one-state solutions, although relatively rare $(27 \%)$, were more common than in Pre $(3 \%)$. When analysis was restricted to the majority of Post trials in which ensemble firing progressed through both states, meanwhile, it became clear that the state-to-state transition occurred earlier in 
A
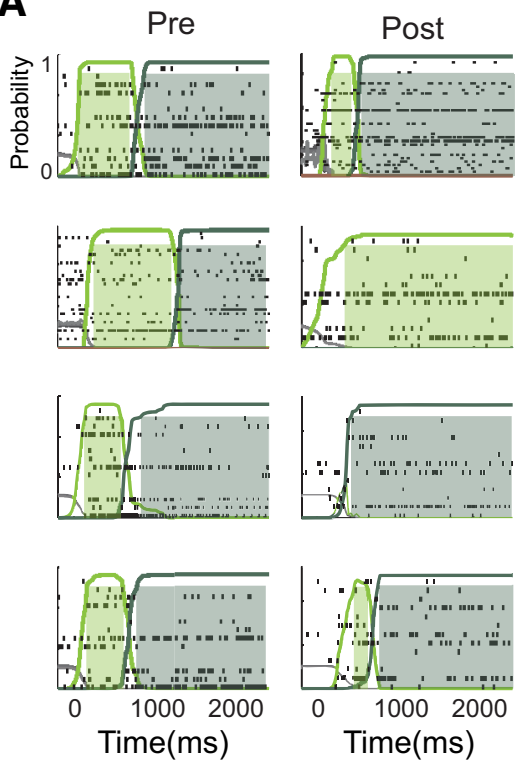

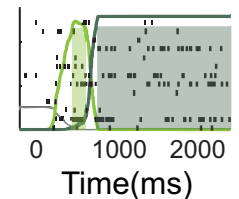

Ext
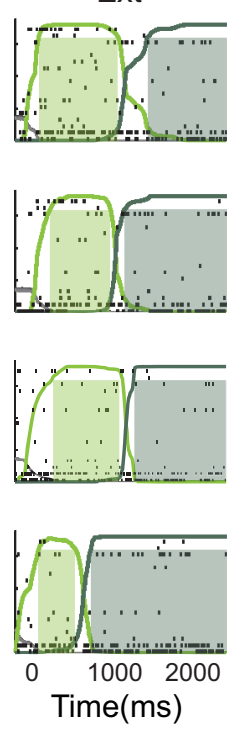

B
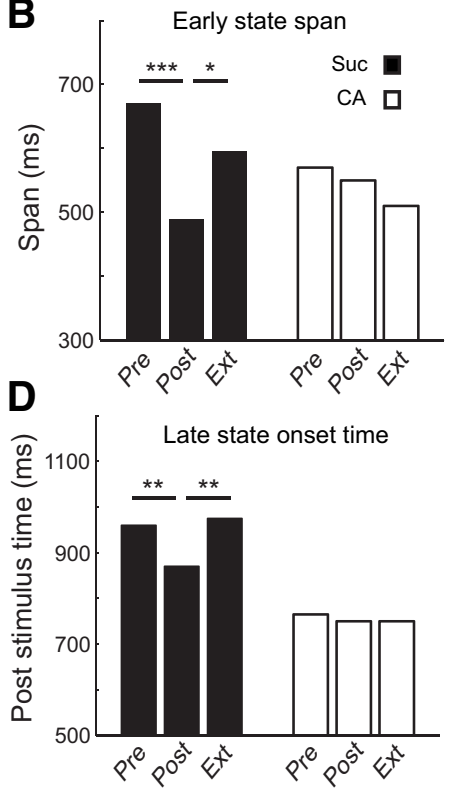

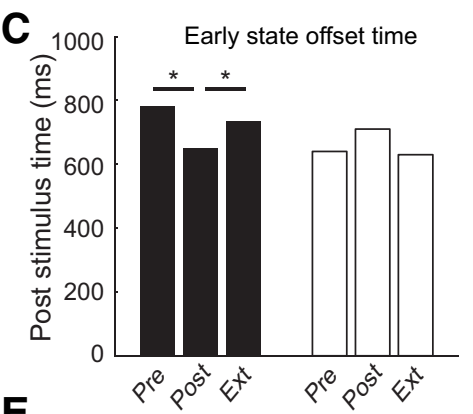

E

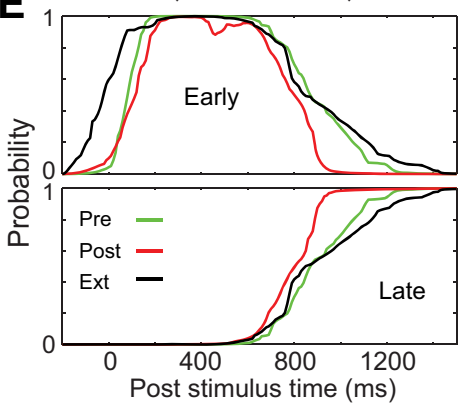

Figure 7. Sucrose ensemble response dynamics shift with CTA and shift back with extinction. $\boldsymbol{A}$, Examples showing that Suc ensemble dynamics differed from session to session. $\boldsymbol{B}-\boldsymbol{D}$, Aspects of Suc response dynamics (dark bars) that tracked behavior included: the span of the early state $(\boldsymbol{B})$; the offset time of early state $(\boldsymbol{C})$; and the onset time of the late state $(\boldsymbol{D})$. CA responses, meanwhile, did not change significantly across sessions (light bars). Kruskal-Wallis with post hoc Wilcoxon rank sum tests, $N=417$. One-way ANOVA: for Suc, $p<0.05 ;$ for $C A, p>0.3 ; p o s t h o c .{ }^{*} p<0.05$. ${ }^{* *} p<0.01$. ${ }^{* * *} p<0.001$. E, Averaged (median, calculated first within and then between rats, $N=6$ ) state probabilities over all 2-state solution Suc trials in the Pre, Post, and Ext sessions (green, red, and black, respectively) showing the shortening of the early state (above) in Post, which promotes an early emergence of the late state (bellow).

Post than in Pre: the duration of the early state was briefer in Post than in either Pre or Ext (Fig. 7B, dark bars), such that it also ended early (Fig. 7C, dark bars); the onset latency of the late state was correspondingly earlier in Post than in either Pre or Ext (Fig. $7 D$, dark bars). CA response dynamics, meanwhile, remained stable across sessions (Fig. $7 B-D$, light bars), supporting our conclusion that this change reflects specific associative learning regarding Suc palatability. These dynamic patters were robust, remaining stable when the few $(15.8 \%)$ neurons that showed similar responses in Pre and Ext were removed from the neuronal cohort. That is, the similarity of Pre and Ext population dynamics was not attributable to the few single-neuron responses that were similar in Pre and Ext.

A graphical summary of this pattern of results is presented in Figure 7E, which shows the average HMM solution for Suc trials across sessions (specifically, the median probability of early and late states averaged first within and then across rats). The transition from the early taste-specific state to the late taste-specific state clearly displays a "leftward shift" between Pre and Post: both the end of the early state (Fig. $7 E$, top) and the onset of the late state (Fig. 7E, bottom) are earlier in Post. Furthermore, the timing of this shift is entirely "rescued" in Ext sessions. We conclude that the speed of Suc processing changes with CTA and changes back with extinction.

\section{Cortical ensemble responses appropriately reflect behavioral relevance of stimuli}

The phenomenon revealed in Figure $7 E$ likely reflects the newly Suc-averse rat's need to quickly complete early state processing of Suc (activity that is useful for stimulus identification) (Katz et al., 2001; Yoshida and Katz, 2011), so that it can more quickly arrive at the later state, which contains activity related to consumption decisions (Katz et al., 2001; Fontanini and Katz, 2006; Piette et al., 2012; Sadacca et al., 2012; Maier and Katz, 2013). We reasoned that, if ensemble-level processing truly tracks behavior (which in

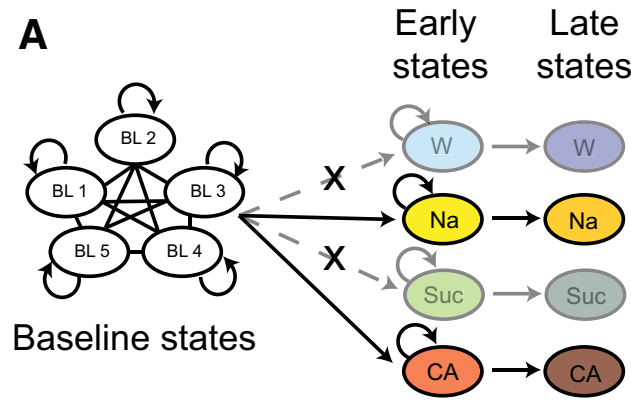

B

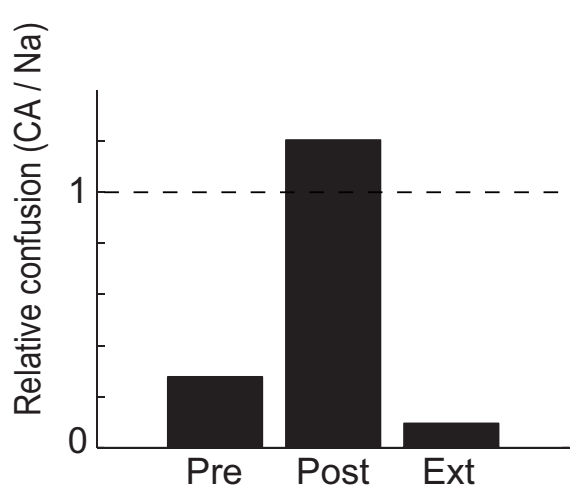

Figure 8. Fast processing of tastes as a signature of aversive stimulus processing. $\boldsymbol{A}$, The reduced HMM containing only $\mathrm{Na}$ and $C A$ state sequences. $\boldsymbol{B}$, Analysis across the entire sucrose trials dataset: Suc was confused with Na much more often than CA ( $y$-axis) in Pre and Ext, and with CA more often than Na in Post. $\chi^{2}(2, N=647)=138.47, p<0.0001$.

this case is a function of palatability), then ensemble Suc responses that do so should most closely resemble those of the stimulus most similar in palatability during that particular session; that is, late-state ensemble Suc responses were predicted to most resemble whichever stimulus causes the most similar be- 
A

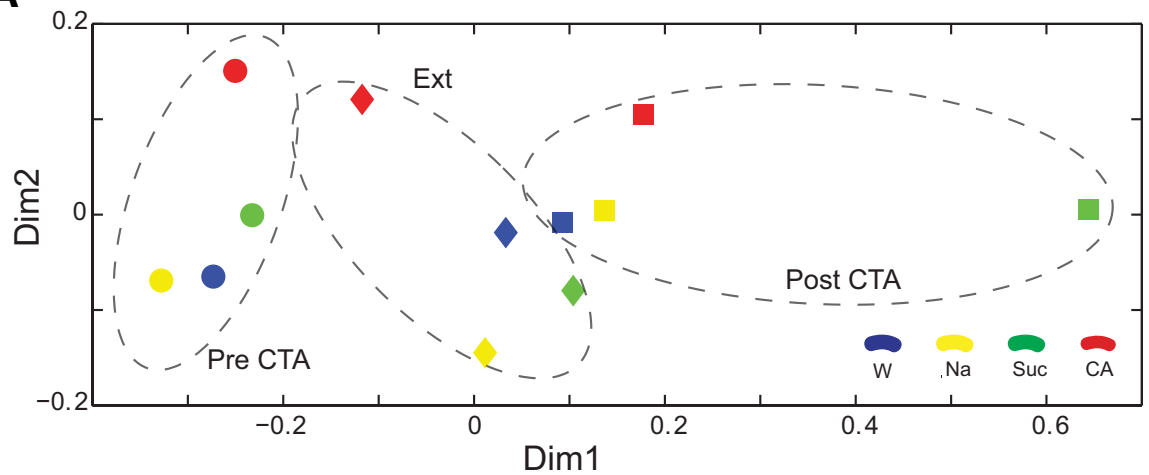

B

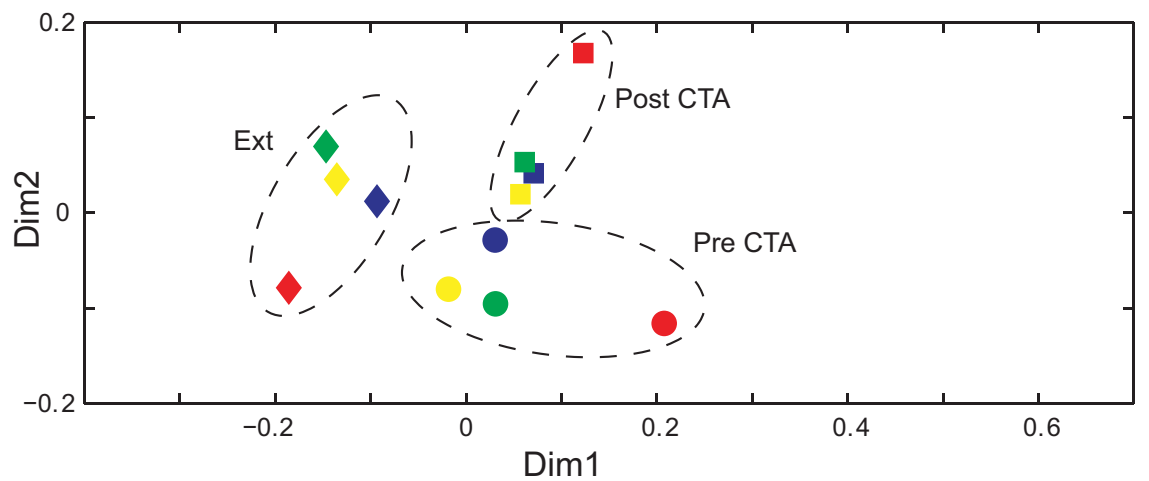

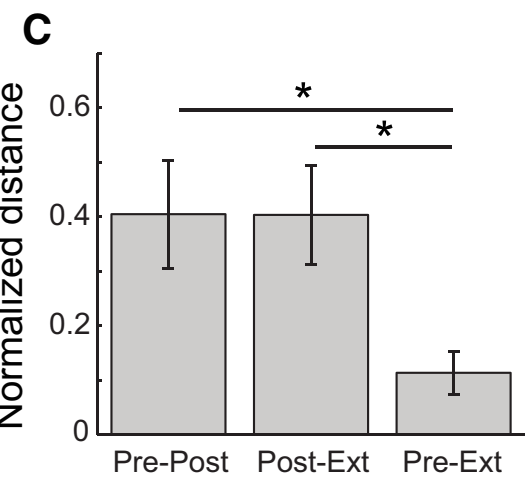

D

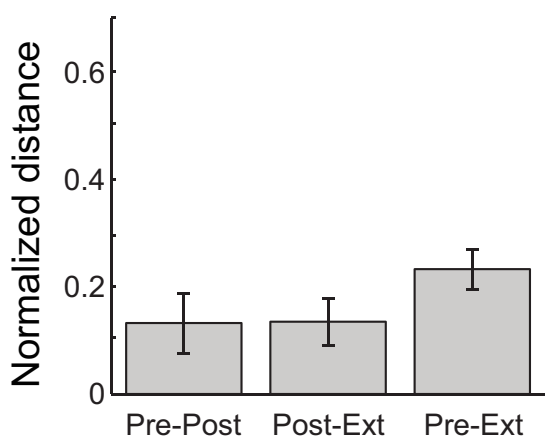

Figure 9. The ensemble "response space" appropriately reflects behavior. $\boldsymbol{A}$, Firing rate in the late state of held neurons $(N=19)$ projected on a $2 D$ taste space, showing the similarity in late-state responses to the different tastes (colors) within different sessions (shapes). $\boldsymbol{B}$, Same analysis as in $\boldsymbol{A}$ for the early state. $\boldsymbol{C}$, The entire taste-to-taste response structure of Pre and Ext in the late state, calculated on the full-dimensionality solution (i.e., before reduction to $2 \mathrm{D}$ for $\boldsymbol{A}, \boldsymbol{B}$ ) are more similar than the other pair of sessions. Overall effect, one-way AN0VA, $p=0.029$, followed by post hoc $t$ tests. ${ }^{*} p<0.05$. Error bars indicate SEM. D, Same analysis as in $\boldsymbol{C}$ for the early state shows no difference in each of the measures. One-way ANOVA, $p=0.39$.

havior at that time (palatable Na in Pre, aversive CA in Post, and palatable $\mathrm{Na}$ once again in Ext) regardless of the specifics of the response to any single stimulus.

We tested this hypothesis in two ways. First, we fit Suc trials to a reduced HMM in which responses were necessarily misclassified as either pre-identified $\mathrm{Na}$ or CA state sequences (Fig. 8A): the network was trained on $\mathrm{Na}$ and CA ensemble responses, after which the remaining pairs of state sequences were made unavailable. This method allowed the creation of a "relative confusion" variable, defined as the ratio of Suc trials misclassified as CA to those misclassified as $\mathrm{Na}$. When this procedure was brought to bear on ensemble responses in Pre, the HMM most often confused Suc responses with $\mathrm{Na}$ (Fig. $8 B$ ); the same procedure used with ensemble responses in Post revealed the opposite pattern: Suc trials were more often confused with CA than Na (Fig. 8B). Finally, in Ext the pattern reversed again (Fig. 8B). Within each session, ensemble Suc responses identified by HMM appropriately tracked behavior, by most resembling whichever other stimulus induced a similar behavior.

We next used MDS to project the entire array of the held neurons' mean responses (or, more precisely, the entire set of pairwise response dissimilarities) from the late (Fig. 9A) and early (Fig. 9B) ensemble states onto a (normalized) 2D plane and calculated the overall relative similarity of Suc responses to $\mathrm{Na}$ and CA responses (Chang and Scott, 1984). Viewed in this manner, late-state responses clearly shifted within the space from session to session, as expected on the basis of the single-neuron results: note in particular the radical movement of Suc from close to $\mathrm{Na}$ and water to far from both in Post (Fig. 9A), whereas early-state responses (which did contain a bit of palatability-related firing) were far more similar in different sessions (Fig. 9B). Equally clear is the fact that the MDS analysis replicated the evidence described above, in that the late ensemble response to Suc was closer in space to that to $\mathrm{Na}$ in both Pre (circles) and Ext (diamonds), but that the reverse was true in Post. Essentially identical results were obtained regardless of whether the analysis included held neurons, in which case the $n$ values for all sessions are of course identical, or all neurons, in which case the $n$ values for all sessions are nonidentical but similar $\left(\mathrm{D}_{\text {pre }}=0.77, \mathrm{D}_{\text {post }}=1.16, \mathrm{D}_{\text {ext }}=\right.$ $0.26, N=19)$, a result that was not observed for the early HMM states $\left(D_{\text {pre }}=0.29, D_{\text {post }}=0.26, D_{\text {ext }}=0.23, N=19\right)$.

These results suggest that the entire set of between-taste relationships (the "shape" of the "response space") in Pre and Ext were similar, despite orientation and scale differences, and despite the obvious differences in the individual responses themselves. To directly test this hypothesis, we normalized Pre, Post, and Ext MDS patterns to fill identical scaling spaces and then calculated the average of all pairwise differences between the "response-space" organizations in each pair of sessions. This analysis revealed that the late-state difference between Pre and Ext is smaller than the differences among other pairs of sessions (Fig. 9C). The layout of perceptual taste space reflected in late state firing faithfully tracks behavior (in a manner that is not true for the early state; Fig. 9D). This result was not significantly changed when neuron-to-neuron differences in response magnitudes and variances were normalized before spatial analysis, a procedure that changed the operative distances from Euclidean to Mahalanobis (Sheinberg and Logothetis, 1997), although this 
normalization, which magnified the impact of small and insignificant responses, inevitably added noise to the re-analysis.

The summary is counter-intuitive: single-neuron responses that do not themselves track behavior combine to form dynamic population responses that do. The fact that responses to all tastes changed somewhat with experience (see Discussion) served to allow the organization of responses in each session to appropriately reflect the behaviors engendered by the tastes.

\section{Discussion}

Our results reconcile two well-supported but seemingly contradictory suggestions: they provide novel, direct confirmation of the suggestion that extinction is a wholly new learning experience: that neural response plasticity underlying extinction is not an "unlearning" of the response plasticity underlying the original learning itself. At the same time, they reveal that the learningrelated evolution of ensemble sensory neural responses, ensemble responses that are composed of single-neuron responses that do not faithfully track behavior, are indeed intimately related to the responses that those stimuli inspire but that this fidelity can be appreciated only at the level of population coding.

A great deal of indirect evidence demonstrates that extinction must not return an animal's neural responses to a naive state. The fact that extinguished learning is reacquired with far less training than was required for the initial learning (Rescorla, 2002; Weidemann and Kehoe, 2003; Jirenhed et al., 2007), for instance, suggests that the extinction leaves some aspect of the original learning intact. Such findings support the prediction that a single neuron's responses to a postextinction stimulus will be distinct from that same single neuron's naive response. Only with stable chronic microwire recordings and a paradigm in which both learning and extinction happen in single trials, however, is it now possible to test and confirm this prediction.

But whereas these single-neuron responses change with each new experience, reflecting the ongoing plasticity processes that are induced by such experiences (Santini et al., 2004), cortical ensemble output stably reflects the similarity of Pre and Ext behavior. The dynamics of ensemble responses, which reflect the rat's gradual processing of the taste (first appreciating the fact that a stimulus is present on the tongue, then apprehending the identity of that stimulus, and finally deciding on the palatability/ importance of the stimulus), become compressed in time after CTA and reexpand with extinction. Although it might be expected that neophobia (the distrust of novel tastes) (Domjan and Gillan, 1976) would lead rats to dislike Suc at first and thus might lead Pre to be distinct from both Post and Ext, this is not what we observed in the ensemble data: it appears likely that preexposure to tastes other than Suc, such as rats received in our training regimen, may have effectively eliminated neophobia (Miller and Holzman, 1981).

This compression of response dynamics, which suggests rapid processing of the newly aversive Suc, is consistent with the oftdiscussed fact that rats are capable of fast rejection of stimuli to which they have learned an aversion (Halpern and Tapper, 1971). It is in the rat's best interest to speed evaluation of a potentially toxic fluid, so that said fluid might be more quickly ejected from the mouth. Although the shift shown in Figure 7E does not fully account for the fastest possible behavioral responses (Halpern and Tapper, 1971), this fact likely reflects differences in specific paradigm: when a rat is allowed to acquire tastes at a lick spout, as opposed to receiving them through intraoral cannulae (as was done during our neural data collection), response dynamics may be further compressed (Stapleton et al., 2006; Samuelsen et al.,
2012). Further work will examine the source of this speeded processing, which is likely external to GC itself, perhaps in basolateral amygdala, which calculates a chemosensory stimulus' palatability earlier in the response than cortex (Fontanini et al., 2009), is biased toward aversive stimuli (Livneh and Paz, 2012), is responsible for passing this information to cortex (Piette et al., 2012), and is vital for CTA (Lasiter and Glanzman, 1985; Yamamoto et al., 1995; Rollins et al., 2001; Bahar et al., 2003; St Andre and Reilly, 2007).

Finally, our results reveal that the output of cortical networks, although changed by each experience, maintain coherence at the population level, the "response space" (the relationship among the responses to different stimuli within an individual session), accurately reflects the meaning of the stimuli. This provides a rationale for the fact that neural responses to $\mathrm{CA}$, which change less than those to Suc in this paradigm, are not $100 \%$ stable across learning and extinction of a Suc CTA; subtle changes in CA (and $\mathrm{Na}$; data not shown) responses specifically allow the similarity of network responses that output to induce similar behaviors to be maintained across experience. Cortical networks provide stable information to downstream neurons, and this stability can be used to maintain stable behavior in the face of experience-related plasticity.

\section{References}

Abeles M, Bergman H, Gat I, Meilijson I, Seidemann E, Tishby N, Vaadia E (1995) Cortical activity flips among quasi-stationary states. Proc Natl Acad Sci U S A 92:8616-8620. CrossRef Medline

Bahar A, Samuel A, Hazvi S, Dudai Y (2003) The amygdalar circuit that acquires taste aversion memory differs from the circuit that extinguishes it. Eur J Neurosci 17:1527-1530. CrossRef Medline

Barnes DC, Hofacer RD, Zaman AR, Rennaker RL, Wilson DA (2008) Olfactory perceptual stability and discrimination. Nat Neurosci 11:13781380. CrossRef Medline

Berman DE, Dudai Y (2001) Memory extinction, learning anew, and learning the new: dissociations in the molecular machinery of learning in cortex. Science 291:2417-2419. CrossRef Medline

Bouton ME (2004) Context and behavioral processes in extinction. Learn Mem 11:485-494. CrossRef Medline

Chang FC, Scott TR (1984) Conditioned taste aversions modify neural responses in the rat nucleus tractus solitarius. J Neurosci 4:1850-1862. Medline

Christensen TA, Pawlowski VM, Lei H, Hildebrand JG (2000) Multi-unit recordings reveal context-dependent modulation of synchrony in odorspecific neural ensembles. Nat Neurosci 3:927-931. CrossRef Medline

Churchland MM, Yu BM, Cunningham JP, Sugrue LP, Cohen MR, Corrado GS, Newsome WT, Clark AM, Hosseini P, Scott BB, Bradley DC, Smith MA, Kohn A, Movshon JA, Armstrong KM, Moore T, Chang SW, Snyder LH, Lisberger SG, Priebe NJ, et al. (2010) Stimulus onset quenches neural variability: a widespread cortical phenomenon. Nat Neurosci 13:369378. CrossRef Medline

Churchland MM, Cunningham JP, Kaufman MT, Foster JD, Nuyujukian P, Ryu SI, Shenoy KV (2012) Neural population dynamics during reaching. Nature 487:51-56. CrossRef Medline

Deadwyler SA, Hampson RE (1997) The significance of neural ensemble codes during behavior and cognition. Annu Rev Neurosci 20:217-244. CrossRef Medline

De la Casa G, Lubow RE (1995) Latent inhibition in conditioned taste aversion: the roles of stimulus frequency and duration and the amount of fluid ingested during preexposure. Neurobiol Learn Mem 64:125-132. CrossRef Medline

Domjan M, Gillan D (1976) Role of novelty in the aversion for increasingly concentrated saccharin solutions. Physiol Behav 16:537-542. CrossRef Medline

Fontanini A, Katz DB (2006) State-dependent modulation of time-varying gustatory responses. J Neurophysiol 96:3183-3193. CrossRef Medline

Fontanini A, Grossman SE, Figueroa JA, Katz DB (2009) Distinct subtypes of basolateral amygdala taste neurons reflect palatability and reward. J Neurosci 29:2486-2495. CrossRef Medline 
Freeman WJ (2000) Mesoscopic neurodynamics: from neuron to brain. J Physiol Paris 94:303-322. CrossRef Medline

Grossman SE, Fontanini A, Wieskopf JS, Katz DB (2008) Learning-related plasticity of temporal coding in simultaneously recorded amygdalacortical ensembles. J Neurosci 28:2864-2873. CrossRef Medline

Halpern BP, Tapper DN (1971) Taste stimuli: quality coding time. Science 171:1256-1258. CrossRef Medline

Herry C, Ciocchi S, Senn V, Demmou L, Müller C, Lüthi A (2008) Switching on and off fear by distinct neuronal circuits. Nature 454:600-606. CrossRef Medline

Jirenhed DA, Bengtsson F, Hesslow G (2007) Acquisition, extinction, and reacquisition of a cerebellar cortical memory trace. J Neurosci 27:24932502. CrossRef Medline

Jones LM, Fontanini A, Sadacca BF, Miller P, Katz DB (2007) Natural stimuli evoke dynamic sequences of states in sensory cortical ensembles. Proc Natl Acad Sci U S A 104:18772-18777. CrossRef Medline

Katz DB, Simon SA, Nicolelis MA (2001) Dynamic and multimodal responses of gustatory cortical neurons in awake rats. J Neurosci 21:44784489. Medline

Kemere C, Santhanam G, Yu BM, Afshar A, Ryu SI, Meng TH, Shenoy KV (2008) Detecting neural-state transitions using hidden Markov models for motor cortical prostheses. J Neurophysiol 100:2441-2452. CrossRef Medline

Lasiter PS, Glanzman DL (1985) Cortical substrates of taste aversion learning: involvement of dorsolateral amygdaloid nuclei and temporal neocortex in taste aversion learning. Behav Neurosci 99:257-276. CrossRef Medline

Livneh U, Paz R (2012) Aversive-bias and stage-selectivity in neurons of the primate amygdala during acquisition, extinction, and overnight retention. J Neurosci 32:8598-8610. CrossRef Medline

Maier JX, Katz DB (2013) Neural dynamics in response to binary taste mixtures. J Neurophysiol 109:2108-2117. CrossRef Medline

Mazor O, Laurent G (2005) Transient dynamics versus fixed points in odor representations by locust antennal lobe projection neurons. Neuron 48: 661-673. CrossRef Medline

McCaughey SA, Giza BK, Nolan LJ, Scott TR (1997) Extinction of a conditioned taste aversion in rats: II. Neural effects in the nucleus of the solitary tract. Physiol Behav 61:373-379. CrossRef Medline

Miller P, Katz DB (2010) Stochastic transitions between neural states in taste processing and decision-making. J Neurosci 30:2559-2570. CrossRef Medline

Miller P, Katz DB (2013) Accuracy and response-time distributions for decision-making: linear perfect integrators versus nonlinear attractor-based neural circuits. J Comput Neurosci 35:261-294. CrossRef Medline

Miller RR, Holzman AD (1981) Neophobias and conditioned taste aversions in rats following exposure to novel flavors. Anim Learn Behav 9:89100. CrossRef

Nicolelis MA, Dimitrov D, Carmena JM, Crist R, Lehew G, Kralik JD, Wise SP (2003) Chronic, multisite, multielectrode recordings in macaque monkeys. Proc Natl Acad Sci U S A 100:11041-11046. CrossRef Medline

Orban G, Fiser J, Aslin RN, Lengyel M (2008) Bayesian learning of visual chunks by human observers. Proc Natl Acad Sci U S A 105:2745-2750. CrossRef Medline

Piette CE, Baez-Santiago MA, Reid EE, Katz DB, Moran A (2012) Inactivation of basolateral amygdala specifically eliminates palatability-related information in cortical sensory responses. J Neurosci 32:9981-9991. CrossRef Medline

Ponce-Alvarez A, Nácher V, Luna R, Riehle A, Romo R (2012) Dynamics of cortical neuronal ensembles transit from decision making to storage for later report. J Neurosci 32:11956-11969. CrossRef Medline

Quirk GJ (2002) Memory for extinction of conditioned fear is long-lasting and persists following spontaneous recovery. Learn Mem 9:402-407. CrossRef Medline

Rabiner LR (1989) A tutorial on hidden markov models and selected applications in speech recognition. Proc IEEE 77:257-285. CrossRef

Rescorla RA (1997) Response-inhibition in extinction. Q J Exp Psychol 50B:238-252.

Rescorla RA (2002) Savings tests: separating differences in rate of learning from differences in initial levels. J Exp Psychol Anim Behav Process 28: 369-377. CrossRef Medline

Rollins BL, Stines SG, McGuire HB, King BM (2001) Effects of amygdala lesions on body weight, conditioned taste aversion, and neophobia. Physiol Behav 72:735-742. CrossRef Medline

Sadacca BF, Rothwax JT, Katz DB (2012) Sodium concentration coding gives way to evaluative coding in cortex and amygdala. J Neurosci 32 9999-10011. CrossRef Medline

Samuelsen CL, Gardner MP, Fontanini A (2012) Effects of cue-triggered expectation on cortical processing of taste. Neuron 74:410-422. CrossRef Medline

Santini E, Ge H, Ren K, Peña de Ortiz S, Quirk GJ (2004) Consolidation of fear extinction requires protein synthesis in the medial prefrontal cortex. J Neurosci 24:5704-5710. CrossRef Medline

Sheinberg DL, Logothetis NK (1997) The role of temporal cortical areas in perceptual organization. Proc Natl Acad Sci U S A 94:3408-3413. CrossRef Medline

St Andre J, Reilly S (2007) Effects of central and basolateral amygdala lesions on conditioned taste aversion and latent inhibition. Behav Neurosci 121: 90-99. CrossRef Medline

Stapleton JR, Lavine ML, Wolpert RL, Nicolelis MA, Simon SA (2006) Rapid taste responses in the gustatory cortex during licking. J Neurosci 26:4126-4138. CrossRef Medline

Weidemann G, Kehoe EJ (2003) Savings in classical conditioning in the rabbit as a function of extended extinction. Learn Behav 31:49-68. CrossRef Medline

Yamamoto T, Yuyama N, Kato T, Kawamura Y (1985) Gustatory responses of cortical neurons in rats: II. Information processing of taste quality. J Neurophysiol 53:1356-1369. Medline

Yamamoto T, Fujimoto Y, Shimura T, Sakai N (1995) Conditioned taste aversion in rats with excitotoxic brain lesions. Neurosci Res 22:31-49. CrossRef Medline

Yasoshima Y, Yamamoto T (1998) Short-term and long-term excitability changes of the insular cortical neurons after the acquisition of taste aversion learning in behaving rats. Neuroscience 84:1-5. CrossRef Medline

Yoshida T, Katz DB (2011) Control of prestimulus activity related to improved sensory coding within a discrimination task. J Neurosci 31:41014112. CrossRef Medline

Ziv Y, Burns LD, Cocker ED, Hamel EO, Ghosh KK, Kitch LJ, El Gamal A, Schnitzer MJ (2013) Long-term dynamics of CA1 hippocampal place codes. Nat Neurosci 16:264-266. CrossRef Medline 